\title{
Temporal Trends of Soil Organic Carbon and Total Nitrogen Losses in Seasonally Frozen Zones of Northeast China: Responses to Long-Term Conventional Cultivation (1965-2010)
}

\author{
Xiao Pu $\cdot$ Jing Xie $\cdot$ Hongguang Cheng $\cdot$ Shengtian Yang
}

Received: 6 May 2014 / Accepted: 13 October 2014 / Published online: 1 November 2014

(C) Springer International Publishing Switzerland 2014

\begin{abstract}
Knowledge is limited on soil organic carbon (SOC) and total nitrogen (TN) dynamics shaped by seasonal freezing-thawing cycles under long-term conventional cultivation. This study aimed to elaborate temporal variability of SOC and TN in the plow layer of agricultural soils employing a dataset of a long-term observation (1965-2010). Cumulative losses were calculated via mass balance equation. With the aid of the autoregression integrated moving average model (ARIMA), time series of historical and impending variations of SOC and TN levels were simulated and depicted. Results revealed that SOC and TN contents decreased by 15 and $42 \%$, respectively. Annual nutrient variations exhibited deteriorating tendencies with fluctuations ranging within -745 and $759 \mathrm{~kg} \mathrm{C} \mathrm{ha}^{-1}$ year $^{-1}$ and -432 and $35 \mathrm{~kg} \mathrm{~N} \mathrm{ha}^{-1}$ year $^{-1}$, respectively. SOC presence was strictly regulated by $\mathrm{N}$ input following a regional pattern. Chemical fertilization, combined with crop residue compost, boosted SOC and TN enrichment, but raised the loss risks. Involvement of green manure/fallow treatment with 1-year frequency in crop rotations favored SOC and TN sequestration. Paddy management was beneficial for SOC accumulation. ARIMA modeling demonstrated annual release rates of $468 \mathrm{~kg} \mathrm{C} \mathrm{ha}^{-1}$ for SOC and $214 \mathrm{~kg} \mathrm{~N}^{-1}$ for TN in subsequent 10 years. The generated algorithms provided a tool to estimate regional SOC and TN losses following cultivation, and to evaluate soil fertility.
\end{abstract}

Keywords Soil organic carbon - Total nitrogen · ARIMA · Seasonally frozen soils · Conventional cultivation

$\mathrm{X} . \mathrm{Pu}(\bowtie)$

College of Resource, Environment and Tourism, Capital Normal University, Beijing 100048, China e-mail: xiao.pu@cnu.edu.cn

X. Pu $\cdot$ S. Yang

State Key Laboratory of Remote Sensing Science, School of Geography, Beijing Normal University, Beijing 100875, China

J. Xie

Chinese Academy for Environmental Planning, Beijing 100012, China

H. Cheng

School of Environment, Beijing Normal University, Beijing 100875, China 


\section{Introduction}

Massive anthropogenic activities such as non-renewable resources consumption and native vegetation clearance for reclamation have enhanced global climate change and environmental pollution subsequent to elevated carbon (C) and nitrogen (N) gaseous emission (Lal 2004). Migration and transformation of $\mathrm{C}$ and $\mathrm{N}$ in soils are vital in balancing natural and artificial ecosystems, and regarded as important constituents of global cycles (Davidson and Janssens 2006; Houghton et al. 1999; Tiessen et al. 1994). C and N biogeochemical cycles in terrestrial ecosystems are of high interest, because they potentially play pivotal roles in global warming and in the contamination of surface and underground water (Lal 2004; Tiessen et al. 1994).

Specifically, agricultural soils are proved to be crucial in the adjustment of global $\mathrm{C}$ and $\mathrm{N}$ cycles for mitigating climate warming, acting as sinks (Ding et al. 2004; Halvorson et al. 2002; Heenan et al. 2004). Agricultural management practices have stimulated the conversion from primeval forest and raw grassland to cropland (Smith et al. 2007). Highly intensive developments of arable lands have undermined original $\mathrm{C}$ and $\mathrm{N}$ balances and exacerbated ecosystem degradation, posing serious threats to human survival.

Agricultural practices result in massive $C$ decline in soils. It has been reported that, $\sim 4.0 \times$ $10^{16} \mathrm{~kg}$ C of the global total $\mathrm{C}$ reduction was induced by tillage and other cultivation modes in the $1990 \mathrm{~s}$, part of which was gaseous $\mathrm{C}$ emitting to the atmosphere at a rate of $1.6 \times 10^{15} \mathrm{~kg} \mathrm{C}$ year $^{-1}$ (Smith 2008). Based on the data of the 2nd national soil survey of China (1982-1985), agricultural practices led to dramatic soil organic carbon (SOC) loss $\left(\sim 7.0 \times 10^{15} \mathrm{~kg} \mathrm{C}\right)$ in the topsoil within a depth of $1 \mathrm{~m}$. Thus, the reduction of SOC caused by land-use change in China accounted for $9.5 \%$ of the total global decline value (Wu et al. 2003). In the topsoil within a depth of $30 \mathrm{~cm}$, the decreased SOC rate that has resulted from agricultural practices presented approximately $1.5 \times 10^{4} \mathrm{~kg} \mathrm{C}$ year $^{-1}$ (Song et al. 2005). N fertilizer application plays a significant role in non-point source pollution (NPSP). $\mathrm{N}$ is prone to loss in dissolved and particulate forms. Remarkably elevated $\mathrm{N}$ in surface runoff results in water quality deterioration and eutrophication ( $\mathrm{Ng}$ Kee Kwong et al. 2002). In Western Europe, it was reported that $37-82 \%$ of total nitrogen (TN) in surface streams initiated from agricultural practices (Smith et al. 2001). The loss rate of TN in purple soils of China was estimated at $44.34 \mathrm{~kg} \mathrm{ha}^{-1}$ year $^{-1}$ (Zhu et al. 2006). With this view, many studies have been conducted to explore $\mathrm{C}$ and $\mathrm{N}$ sequestration in diverse types of soils under varying climatic conditions as affected by long- or short-term cultivation (Halvorson et al. 2002; Heenan et al. 2004; Mazzoncini et al. 2011; Sainju et al. 2008).

However, most previous studies refer to tropic or warm temperate areas, and knowledge is limited in cold temperate zones with seasonal freeze-thaw cycles. Sanjiang Plain, one of the most pivotal national agricultural areas, is located in northeastern China at medium to high latitudes. The enduring long-term iterative freeze-thaw cycles might have affected soil aggregation, soil physical and chemical properties, hydrological processes, and nutrient transport characteristics.

Model approach is an important tool for simulating the variability of soil nutrients, which can provide data support for scientific decision-making related to environmental protection and agricultural management. Specifically, the autoregression integrated moving average model (ARIMA) is competent for time/frequency-dependent variables with data sequence (Brockwell and Davis 2009). However, limited knowledge exists on application of ARIMA model on SOC and TN variations in a long-term period. Therefore, the objective of this paper was to employ ARIMA model for characterizing temporal trends of SOC and TN variations affected by long-term conventional cultivation in seasonally frozen zones of northeastern China. 


\section{Materials and Methods}

\subsection{Study Area}

The study was conducted at Bawujiu agricultural area $\left(47^{\circ} 18^{\prime} \sim 47^{\circ} 50^{\prime} \mathrm{N}\right.$ and $133^{\circ} 50^{\prime} \sim$ $134^{\circ} 33^{\prime} \mathrm{N}$ ) with a surface area of $1,355.5 \mathrm{~km}^{2}$. The area is located along Wusuli River, in the east of Sanjiang Plain and to the north of Wandashan Mountain, northeastern China (Fig. 1). The native terrestrial ecosystems were historically established by Dahurian larch [Larix gmelinii (Rupr.) Rupr.], Manchurian ash (Fraxinus mandshurica Rupr.), and white birch (Betula platyphylla Suk.) prior to high-intensity agricultural practices with conventional cultivation. Lessive soil (Chinese soil taxonomy: Baijiang Soil; USDA: fine, illitic, frigid Mollic Albaqualfs; FAO: Albeluvisol) predominantly occupies $90 \%$ of the cultivated area. The area is characterized as cold temperate and humid to semi-humid continental monsoon climate ( $\mathrm{Pu}$ et al. 2012). The annual average of the active accumulated temperature above $10{ }^{\circ} \mathrm{C}$ reaches $2,439.96{ }^{\circ} \mathrm{C}$. The frost-free period is 138 days, during which the mean frozen soil depth is $141 \mathrm{~cm}$. The long-term annual mean air temperature, precipitation and evaporation are $2.24{ }^{\circ} \mathrm{C}, 555.32$, and $1,002.33 \mathrm{~mm}$, respectively.

\subsection{Agricultural Management Practices}

Fertilization utility (FU) and crop system (CS) were the concerned factors for assessing the effects of conventional cultivation on SOC and TN variations. Three CSs in the period of 1965-1983 comprised a 3-year crop rotation of wheat (Triticum aestivum L.)-wheat-soybean [Glycine max (L.) Merr.] (CS1), a 3-year crop rotation of wheat-oilseed rape (Brassica napus L.)/fallow-soybean (CS2), and a 2-year crop rotation of maize (Zea mays L.)-foxtail millet

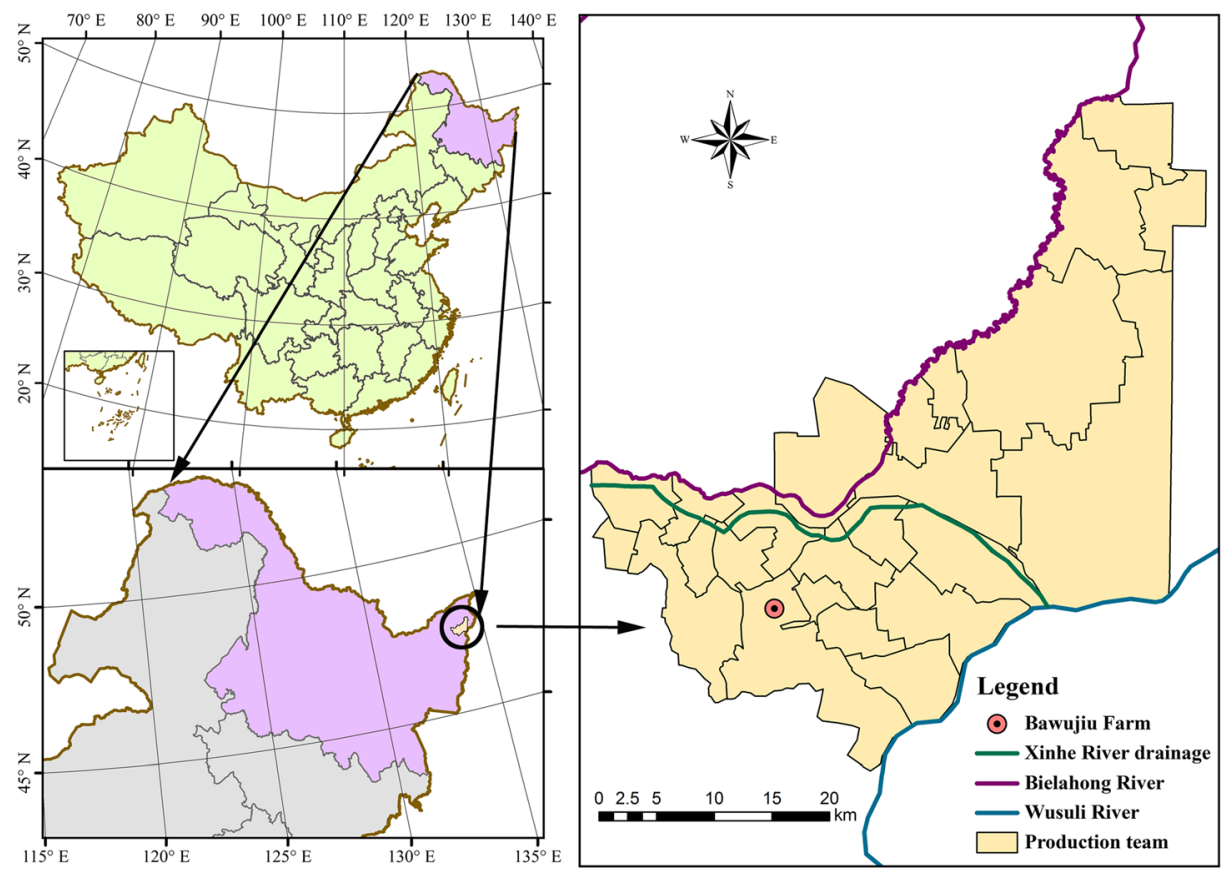

Fig. 1 Map for the location of Bawujiu agricultural area in Heilongjiang Province, Northeastern China 
[Setaria italica (L.) P. Beauv.] (CS3). Similarly, two CSs were categorized as paddy rice (PR) and dry cropland (DC, a 2-year rotation of maize-soybean) for 2005-2010. Crop rotations were continuously applied in the same block during the observation period. In CS2, oilseed rape/fallow treatment without harvest and $\mathrm{N}$ fertilization were arranged triennially to increase biomass returned to soils through cover crops incorporated into the soil with conventional tillage. The dominant vegetation of fallow included Cyperus rotundus L., Deyeuxia langsdorffii (Link) Kunth, and Bolboschoenus maritimus (L.) Palla (= Scirpus maritimus L.). Two fertilizing patterns (FU1: no chemical fertilizer plus little organic manure; FU2: chemical fertilizer with stubble maintenance) were involved in the period of 1965-1983, and two fertilization rates (LFU: low rate; HFU, high rate) compared to the mean value were distinguished for 2005-2010. Due to lack of chemical fertilizer before 1975, manure (human and livestock excrement and poultry litter) was used prior to crop sowing. Granular triple superphosphate, urea, and diammonium phosphate were applied since 1975, with urea being utilized from 1976 onwards ( $\mathrm{Pu}$ et al. 2014). Since then, organic manure had no longer been adopted. Fertilization rate increased remarkably (from $35.85 \mathrm{~kg} \mathrm{~N} \mathrm{ha}^{-1}$ year $^{-1}$ in 1975 to $357 \mathrm{~kg} \mathrm{~N} \mathrm{ha}^{-1}$ year $^{-1}$ in 1983 for dry cropland; from $74.55 \mathrm{~kg} \mathrm{~N} \mathrm{ha}^{-1}$ year $^{-1}$ in 2005 to $180 \mathrm{~kg} \mathrm{~N} \mathrm{ha}^{-1}$ year $^{-1}$ in 2010), while the modes differed (a blend of seeds and fertilizer for wheat, preferential fertilization for soybean and paddy rice, and ditch fertilization for maize and foxtail millet). The general agricultural management practices are summarized by $\mathrm{Pu}$ et al. (2014) and are tabulated in Table 1.

\subsection{Soil Sampling}

The dataset consists of historical records and contemporary observation embodied in a longterm sampling scheme. Soil samples were collected with a manual steel probe (int. diameter $6.5 \mathrm{~cm}$ ) from the plow layer (0-20 cm depth) in mid-October of 1965, 1974, 1978, 1979, $1981,1983,2005,2006,2007,2008$, and 2010 immediately following crop harvest, prior to tillage for the subsequent cultivation of the next year. In the case of 1965-1983, 54 blocks of $100-120 \mathrm{~m}$ length and 50-60 m width were selected dispersedly around the study area. For the period of 2005-2008, 27 blocks for paddy rice and 18 blocks for dry cropland with $60-80 \mathrm{~m}$ length and 50-60 m width were selected. According to annals, the selected blocks were covered by native forest prior to crop systems, and were cultivated in 1964. In each block, three soil cores were randomly taken and thoroughly mixed as a composite sample after the discrete removal of crop residues, thus representing the corresponding block. As a result, a total of 529 soil samples were collected. Upon delivery to the laboratory, soil samples were airdried, ground, and sieved (using a $2 \mathrm{~mm}$ mesh) for subsequent chemical analysis.

\subsection{Chemical Analyses}

A redox titration procedure was employed for determining SOC concentration, described as Tinsley's wet combustion method (Tinsley 1950). Soil samples were heated with an excessive amount of a mixture of potassium dichromate and sulphuric acid at $170-180{ }^{\circ} \mathrm{C}$ for $5 \mathrm{~min}$. Redundant oxidant was then titrated by ferrous ammonium sulfate with an indicator of four drops of ferrous o-phenanthroline. SOC concentration could be calculated according to the amount of oxidant consumed. TN was measured by a modified approach known as the microKjeldahl method (Bremner 1960). A weighed amount of soil was digested in a concentrated sulfuric acid solution heated to rolling boil. Subsequently, the ammonium in the digests was collected in a boric acid solution after distillation and then determined by $\mathrm{H}_{2} \mathrm{SO}_{4}$ titration. Statistical descriptions of the observations were presented in Table 2. 
Table 1 Descriptions of conventional agricultural management practices adopted in the present study

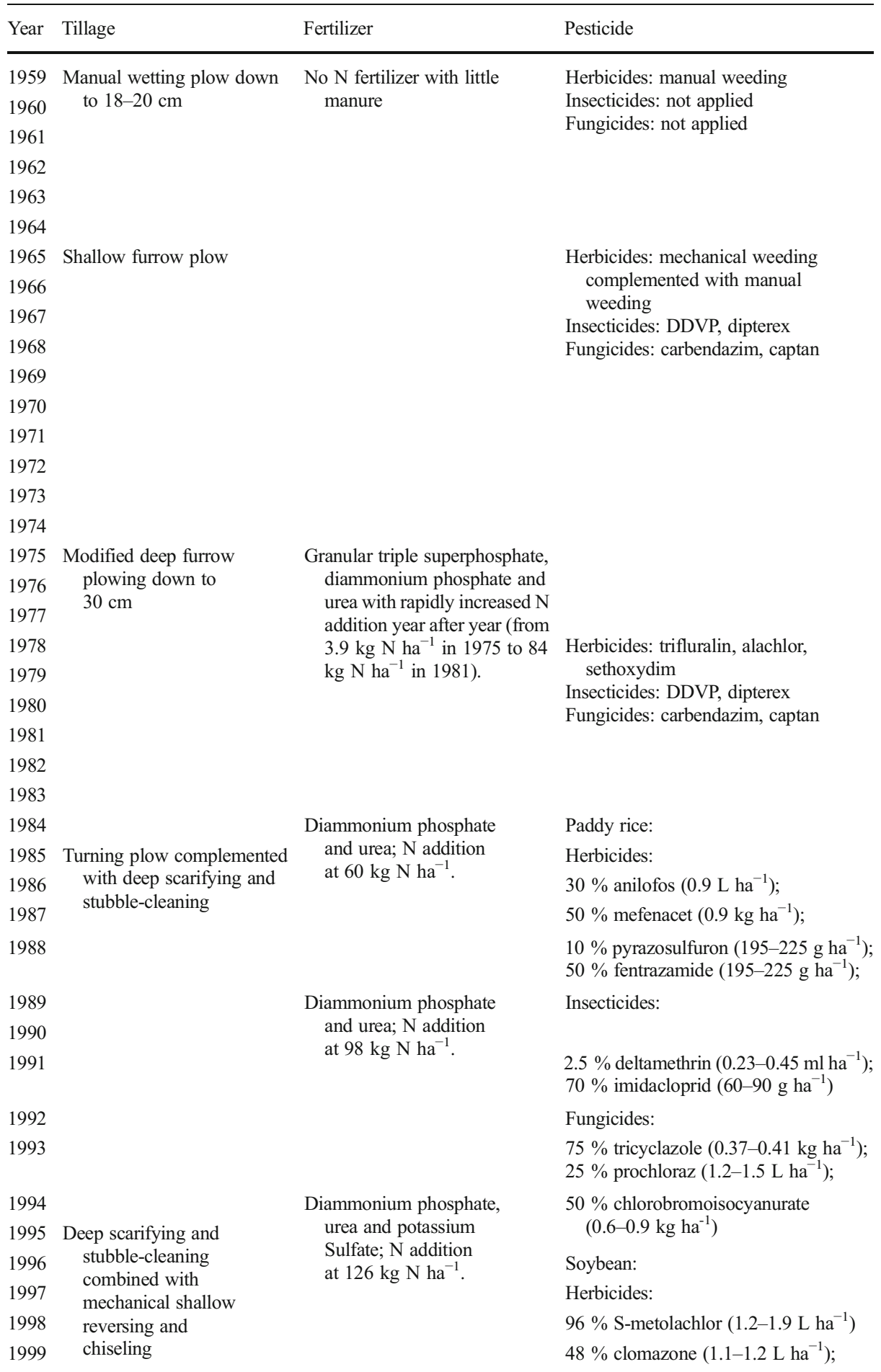


Table 1 (continued)

\begin{tabular}{|c|c|c|c|}
\hline Year & Tillage & Fertilizer & Pesticide \\
\hline 2000 & \multirow{14}{*}{ Deep scarifying and chiseling } & \multirow{14}{*}{$\begin{array}{l}\text { Diammonium phosphate, } \\
\text { urea and potassium } \\
\text { Sulfate; } \mathrm{N} \text { addition } \\
\text { at } 182 \mathrm{~kg} \mathrm{~N} \mathrm{ha}^{-1} \text {. }\end{array}$} & Insecticides: \\
\hline 2001 & & & $2.5 \%$ deltamethrin $\left(0.3-0.45 \mathrm{ml} \mathrm{ha}^{-1}\right)$; \\
\hline 2002 & & & $5 \%$ esfenvalerate $\left(0.23-0.38 \mathrm{~L} \mathrm{ha}^{-1}\right)$ \\
\hline 2003 & & & Fungicides: \\
\hline 2004 & & & $25 \%$ prochloraz $\left(1.2-1.5 \mathrm{~L} \mathrm{ha}^{-1}\right)$ \\
\hline 2005 & & & $80 \%$ carbendazim $\left(0.75 \mathrm{~kg} \mathrm{ha}^{-1}\right)$ \\
\hline 2006 & & & Maize: \\
\hline 2007 & & & Herbicides: \\
\hline 2008 & & & $96 \%$ S-metolachlor $\left(0.8-1.2 \mathrm{~L} \mathrm{ha}^{-1}\right)$ \\
\hline 2009 & & & $38 \%$ atrazine $\left(1.5 \mathrm{~L} \mathrm{ha}^{-1}\right)$ \\
\hline 2010 & & & Insecticides: \\
\hline 2011 & & & $5 \%$ esfenvalerate $\left(0.23-0.3 \mathrm{~L} \mathrm{ha}^{-1}\right)$ \\
\hline 2012 & & & Fungicides: \\
\hline 2013 & & & $80 \%$ carbendazim $\left(0.75 \mathrm{~kg} \mathrm{ha}^{-1}\right)$ \\
\hline
\end{tabular}

Table 2 Statistical description for SOC and TN contents in a separate year during the observation period $\left(\mathrm{mg} \mathrm{g}^{-1}\right)$

\begin{tabular}{llrlrrrrr}
\hline Year & Nutrient & Mean & Std & CV \% & Max & Min & Skewness & Kurtosis \\
\hline 1965 & SOC & 26.17 & 3.72 & 13.82 & 34.30 & 18.06 & 0.21 & -0.68 \\
& TN & 3.40 & 0.67 & 0.45 & 4.94 & 1.79 & 0.08 & -0.08 \\
1974 & SOC & 25.63 & 3.64 & 13.25 & 37.18 & 15.50 & 0.01 & 0.65 \\
& TN & 2.11 & 0.30 & 0.09 & 2.87 & 1.40 & 0.24 & -0.11 \\
1978 & SOC & 24.69 & 3.78 & 14.25 & 38.32 & 17.40 & 0.72 & 0.78 \\
& TN & 2.47 & 1.00 & 1.01 & 5.40 & 1.04 & 0.08 & 0.29 \\
1979 & SOC & 24.63 & 2.83 & 7.98 & 28.14 & 15.20 & -0.74 & 0.39 \\
& TN & 2.58 & 0.45 & 0.20 & 3.41 & 1.43 & -0.62 & 0.88 \\
1981 & SOC & 25.57 & 4.79 & 22.97 & 35.27 & 13.23 & 0.14 & -0.82 \\
& TN & 2.84 & 0.66 & 0.43 & 4.90 & 1.35 & 0.12 & 0.36 \\
1983 & SOC & 28.57 & 6.23 & 38.81 & 40.43 & 17.40 & 0.09 & -0.92 \\
& TN & 3.02 & 1.18 & 1.38 & 5.49 & 1.20 & 0.45 & -0.03 \\
2005 & SOC & 20.27 & 5.07 & 25.65 & 35.90 & 11.60 & 0.19 & 0.52 \\
& TN & 2.09 & 0.26 & 0.07 & 2.68 & 1.56 & -0.05 & -0.19 \\
2006 & SOC & 22.14 & 2.78 & 7.71 & 26.45 & 17.81 & 0.05 & -0.97 \\
& TN & 2.09 & 0.88 & 0.78 & 5.09 & 1.37 & 0.11 & 0.73 \\
2007 & SOC & 23.30 & 5.19 & 26.95 & 43.62 & 12.18 & 0.26 & 0.70 \\
& TN & 1.99 & 0.33 & 0.11 & 3.13 & 1.19 & 0.49 & 0.31 \\
2008 & SOC & 23.20 & 6.13 & 37.55 & 46.93 & 7.31 & 0.13 & 0.27 \\
& TN & 1.97 & 0.36 & 0.13 & 3.32 & 1.16 & 0.32 & 0.19 \\
2010 & SOC & 25.22 & 6.15 & 37.83 & 40.20 & 17.80 & 0.17 & 0.82 \\
& TN & 2.24 & 0.89 & 0.79 & 4.84 & 1.32 & 0.38 & 0.59 \\
\hline
\end{tabular}




\subsection{Data Treatment}

For describing and evaluating variation trends in levels and annual losses of SOC and TN during the period of 1965-2010, the ARIMA model was applied on the discrete raw data from 11 years. The statistical model developed herein does not consider causalities among variables, but investigates temporal trends of variables. After missing values were filled, data sequence on SOC and TN levels and losses were smoothed out using the algorithm of $\mathrm{T} 4253 \mathrm{H}$, due to its advantages in automatically moving and averaging raw data which are superior to other approaches (Zhang 2003). The computing order was determined through auto regression (ACF) and partial regression (PACF) analysis. For elucidating the effects of conventional agricultural practices, Levene's test was adopted to assess homogeneity of variances before analysis. Analysis of variance (ANOVA) was then performed to test differences in SOC and TN. The multivariate general linear model (GLM) procedure was applied to analyze the mean effects of factors. Significant changes in treatment means were determined using Fisher's protected LSD test $(P<0.05)$ for more than two groups, and independent $t$-test (two-tailed, $P<0.05)$ for two groups. Since records on soil nutrients in native forest lands prior to reclamation were not collected, there was lack of background data for comparison. Thus, the soil data in 1965 were taken as references to assess the effects of cultivation. All data for nutrients and selected factors were processed with SPSS 17.0 software package (SPSS Inc., Chicago, IL, USA).

\section{Results and Discussion}

\subsection{Time Series Model Establishment}

\subsubsection{Model Identification and Parameter Estimation}

A time series model strictly requires intact data sequence, thus the missing values ought to be determined prior to subsequent analysis. Several regression approaches in incomplete data records have been developed to account for missing values (Horton and Kleinman 2007). However, absence of data is still at random, because the missing values are determined by the observed quantities. Thereby, modelling assumptions are required when the recorded data is incomplete based on analysis of the existing observations (Brockwell and Davis 2009). In a previous study by Sainju et al. (2008), the linear interpolation mode was adopted when estimating annual $\mathrm{C}$ sequestration rates in a long time period with a data gap. Horton and Kleinman (2007) also suggested that simpler regression approaches could be utilized if the pattern of curves is monotone. In the present study, limited fluctuations of $\mathrm{C}$ and $\mathrm{N}$ variations were observed with time, and no periodicity was found (Table 2). Thus, use of algorithms with specific periodic tendencies would be arbitrary and without scientific evidence to be potentially employed. In view of these, the linear regression mode was employed for simplification, which seems to be sufficient to describe net variations of $\mathrm{C}$ and $\mathrm{N}$ among years during the observation period.

Before parameter estimations, $\mathrm{T} 4253 \mathrm{H}$ and $\log$ transformation enabled data sequence smoothing for time series calculation. ACFs and PACFs of raw data on cumulative SOC and TN losses illustrated that severe smearing phenomenon occurred: the coefficients exceeded the confidence interval when the lag was equal to 12 in both cases (Fig. 2). Therefore, the data sequences were not smooth and required differential processing. The tendencies of seasonal variations were not found as data in individual years were collected, thus the ARIMA (q, d, p) model could be simplified as ARIMA (q, 0, p). 

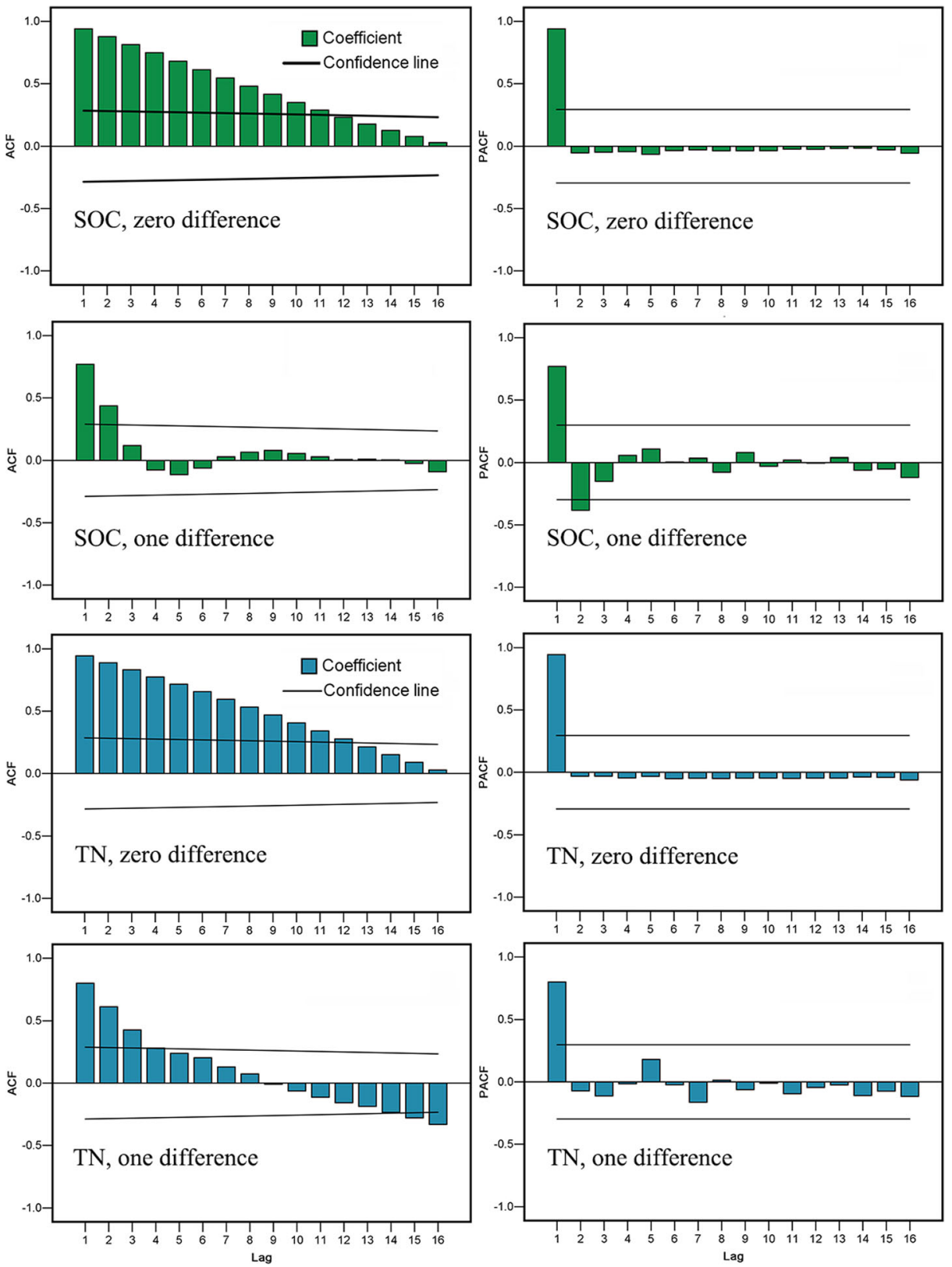

Fig. 2 Sketches for ACF and PACF of SOC or TN cumulative loss in time series with zero and one difference, respectively

The correlation coefficients for data sequences decreased after first difference (Fig. 2). Less than three coefficients were higher than confidence lines ( 3 for SOC and 2 for TN). Consequently, the data sequences were considered satisfactory for subsequent modeling. For cumulative SOC loss, two peaks existed when the lag was equal to 1 and 2, both in ACF and PACF (Fig. 2). However, high correlations were observed between AR1 and AR2 (-0.986), 
and MA1 and MA2 (0.681) as shown in Table 3. Thus, lower orders for both modules could be taken into consideration (Table 3 ).

\subsubsection{Model Evaluation}

Five criteria were used to check model validity: parameter significance, goodness of fitting, parameter independence test, residuals test, and whether the observations were in the confidence interval (Brockwell and Davis 2009; Zhang 2003). Standard errors were calculated via Bartlett's approximation mode. Unconditional least-square mode was employed for prediction. Melard's algorithm was used for parameter estimation, taking Marquardt nonlinear least-square method as the iteration mode. Statistical descriptions and parameter values were tabulated in Table 4. Coefficients of all alternative models were significant at $P<0.05$. After comparing alternative models according to goodness of fit, ARIMA $(2,0,2)$ model was found satisfactory, presenting less standard errors, greater values of log likelihood function, and lower scores in Akaike's information criterion (AIC) and Schwarz's Bayesian criterion (SBC). Additionally, all observations were within $95 \%$ confidence interval when $(2,0,2)$ mode was performed. Note that highly negative correlations were observed between AR1 and AR2 in ARIMA $(2,0,2)$ models for SOC and TN. Nevertheless, the residuals were confirmed not to conform with white noise after AR was lowered to the first order. For this point, Zhang (2003) indicated that the criterion of residuals test for white noise was required to set greater priority when contradictions occurred. Hence, ARIMA $(2,0$, 2) models were recommended and the predictive formulas were:

$$
\begin{aligned}
& \left(1-B_{q}\right)\left(1-B_{p}\right) \ln \left(C_{\mathrm{SOC}}\right)=\left(1-1.509 B_{q}^{1}+0.571 B_{q}^{2}\right)\left(1+0.422 B_{p}^{1}+0.267 B_{p}^{2}\right) \sigma_{\mathrm{SOC}} \\
& \left(1-B_{q}\right)\left(1-B_{p}\right) \ln \left(C_{\mathrm{TN}}\right)=\left(1-1.654 B_{q}^{1}+0.696 B_{q}^{2}\right)\left(1+0.145 B_{p}^{1}+0.341 B_{p}^{2}\right) \sigma_{\mathrm{TN}}
\end{aligned}
$$

where $C$ is cumulative loss of SOC or TN, $B$ is backward shift operator, and $\sigma$ is the random disturbance.

\begin{tabular}{|c|c|c|c|c|c|c|c|c|}
\hline & AR1 & AR2 & MA1 & MA2 & & AR1 & MA1 & MA2 \\
\hline & \multicolumn{4}{|c|}{ ARIMA $(2,0,2)$ for SOC } & \multicolumn{4}{|c|}{ ARIMA $(1,0,2)$ for SOC } \\
\hline AR1 & 1.000 & -0.986 & 0.771 & 0.682 & AR1 & 1.000 & 0.244 & 0.268 \\
\hline AR2 & & 1.000 & -0.762 & -0.659 & MA1 & & 1.000 & 0.652 \\
\hline MA1 & & & 1.000 & 0.681 & MA2 & & & 1.000 \\
\hline MA2 & & & & 1.000 & & & & \\
\hline & \multicolumn{4}{|c|}{$\operatorname{ARIMA}(2,0,2)$ for $\mathrm{TN}$} & \multicolumn{4}{|c|}{$\operatorname{ARIMA}(1,0,2)$ for $\mathrm{TN}$} \\
\hline AR1 & 1.000 & -0.988 & 0.623 & 0.504 & AR1 & 1.000 & 0.147 & 0.123 \\
\hline AR2 & & 1.000 & -0.619 & -0.491 & MA1 & & 1.000 & 0.502 \\
\hline MA1 & & & 1.000 & 0.396 & MA2 & & & 1.000 \\
\hline MA2 & & & & 1.000 & & & & \\
\hline
\end{tabular}

Table 3 The correlation matrix of the modeling strategy with ARIMA for cumulative SOC or TN losses 
Table 4 Parameter estimation and goodness of fitting test of the alternative models

\begin{tabular}{llllll}
\hline & \multicolumn{2}{l}{ Cumulative SOC loss } & & \multicolumn{2}{l}{ Cumulative TN loss } \\
\cline { 2 - 3 } \cline { 5 - 6 } & ARIMA $(1,0,2)$ & ARIMA $(2,0,2)$ & & ARIMA $(1,0,2)$ & ARIMA $(2,0,2)$ \\
\hline AR1 $^{\text {a }}$ & $0.935^{* * *}$ & $1.509^{* * *}$ & & $0.960^{* * *}$ & $1.654^{* * *}$ \\
AR2 & & $-0.571^{* *}$ & & $-0.696^{* * *}$ \\
MA2 & $-0.563^{* * *}$ & $-0.267^{* *}$ & & $-0.541^{* * *}$ & $-0.341^{* *}$ \\
SE $^{\text {b }}$ & 0.217 & 0.207 & & 0.072 & 0.064 \\
Log likelihood $^{*}$ & 5.266 & 7.834 & & 55.749 & 61.702 \\
AIC $^{\mathrm{c}}$ & -0.531 & -3.668 & & -101.497 & -111.405 \\
SBC $^{\text {d }}$ & 8.612 & 7.304 & & -92.354 & -100.433 \\
Resi sig $^{\text {e }}$ & $* *$ & NS & & & NS \\
\hline
\end{tabular}

${ }^{\text {a }}$ Estimated parameter

${ }^{\mathrm{b}}$ Standard error

' Akaike's information criterion

${ }^{\mathrm{d}}$ Schwarz's Bayesian criterion

${ }^{\mathrm{e}}$ Residuals significant, which were determined by Box-Ljung statistics; ${ }^{*} P<0.05,{ }^{* *} P<0.01,{ }^{* * *} P<0.001, N S$ not significant

\subsection{SOC and TN Losses Under Long-Term Conventional Cultivation}

Both SOC and TN stocks declined before 1979 with continuous deterioration in the annual losses (Fig. 3). Since 1980, a rapid growth on the storage occurred. SOC stocks increased by $3.8 \%$ in 1983 compared to 1965 (Fig. 3). A moderate drop was observed by $0.3 \%$ at the initial stage of the experiment (before 1974), followed by a phase of a sharp drop of $2 \%$ (1974-1978). Subsequently, the SOC stock visibly rose since 1980. However, considering 1965 as the base year, the annual SOC loss had been deteriorating before 1980 (209-668 $\mathrm{kg} \mathrm{C} \mathrm{ha}^{-1}$ year $^{-1}$ were lost), just 1 year after the time when positive SOC variation appeared (131-759 $\mathrm{kg} \mathrm{C} \mathrm{ha}^{-1}$ year $^{-1}$ were accumulated).
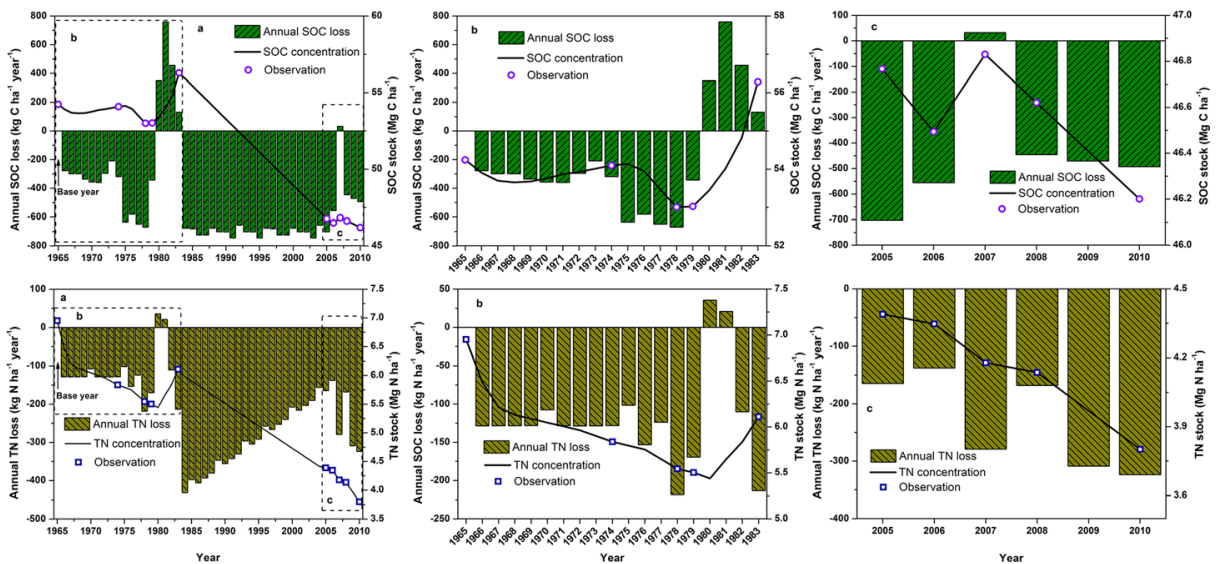

Fig. 3 Stocks and annual loss during the observation period: the entire period of 1965-2010 (a), the long period of 1965-1983 (b), and the short period of 2005-2010 (c) for SOC; the entire period of 1965-2010 (d), the long period of 1965-1983 (e), and the short period of 2005-2010 (f) for TN 
SOC stock still kept deteriorating with a decline of $1.2 \%$ in 2005-2010, ranging from 32 to $702 \mathrm{~kg} \mathrm{C} \mathrm{ha}^{-1}$ year $^{-1}$.

In the case of TN, a sharp drop of $16 \%$ for the early term (before 1974) and a moderate drop of $5 \%$ for the medium term (1975-1978) were observed in the TN stock, respectively (Fig. 3). The TN stock was straight up after 1980. Nevertheless, a $12.1 \%$ drop of TN stock was observed in 1965-1983. Annual TN accumulation continued for 2 years (1980 and 1981). After that, the annual TN loss ranged between 101 and $218 \mathrm{~kg} \mathrm{~N} \mathrm{ha}^{-1}$ year $^{-1}$. The TN stock was determined to change from $4.4 \times 10^{3} \mathrm{~kg} \mathrm{~N} \mathrm{ha}^{-1}$ in 2005 to $3.8 \times 10^{3} \mathrm{~kg} \mathrm{~N}^{-1}$ in 2010 . Correspondingly, the annual TN loss was kept in the range of $138-324 \mathrm{~kg} \mathrm{~N}^{-1} \mathrm{ya}^{-1}$.

Dynamics of SOC and TN cumulative losses were simulated by ARIMA $(2,0,2)$ model (Fig. 4). Considering values between 1965 and 2010, $2.1 \times 10^{4} \mathrm{~kg} \mathrm{C} \mathrm{ha}^{-1}$ of SOC and $9.8 \times$ $10^{3} \mathrm{~kg} \mathrm{~N} \mathrm{ha}^{-1}$ of TN were lost under conventional cultivation. Annual variations exhibited deteriorating tendencies with the fluctuating levels ranging within -745 and $759 \mathrm{~kg} \mathrm{C}$ $\mathrm{ha}^{-1}$ year $^{-1}$ and -432 and $35 \mathrm{~kg} \mathrm{~N} \mathrm{ha}^{-1}$ year $^{-1}$, respectively.

The predictions on SOC and TN cumulative losses indicated that the current rates would continue in the subsequent 10 years (Fig. 4). By the end of 2020, additional amounts of $4.7 \times$ $10^{3} \mathrm{~kg} \mathrm{ha}^{-1}$ of SOC and $2.1 \times 10^{3} \mathrm{~kg} \mathrm{ha}^{-1}$ of TN would be lost, which imply annual releases of $468 \mathrm{~kg} \mathrm{C}^{-1}$ and $214 \mathrm{~kg} \mathrm{~N} \mathrm{ha}^{-1}$.

\subsection{Effects of Long-Term Conventional Cultivation}

Under the current conventional cultivation conditions, SOC and TN variations in the plow layer were positively correlated with fertilizer input (Table 5). Increased fertilization resulted in higher SOC and TN concentrations, but only when crop residues were returned to soils (Alvarez 2005). Higher fertilization rate followed by increased crop biomass production and chemical stabilization was beneficial to higher SOC and TN increments (Halvorson et al. 2002; Mazzoncini et al. 2011). Application of chemical fertilizer with crop residue compost boosted the formation of macro-aggregates which helped stabilizing soil C and N (Sodhi et al. 2009). Freeze-thaw events more severely affected macro-aggregates compared to microaggregates, decreasing soil aggregate stability (Oztas and Fayetorbay 2003; Six et al. 2004). This reciprocating change in physical disruption of soil aggregates magnified the effect of fertilization. SOC increment was reported to approximately follow a pattern: $2 \times 10^{3} \mathrm{~kg} \mathrm{C} \mathrm{ha}^{-1}$ increase per $1 \times 10^{3} \mathrm{~kg} \mathrm{~N}$ ha $^{-1}$ of $\mathrm{N}$ accumulation compared to unfertilized treatment (Alvarez 2005), which could be confirmed in our study (a $2.0 \times 10^{3} \mathrm{~kg} \mathrm{C} \mathrm{ha}^{-1}$ increase of SOC for $1.3 \times$
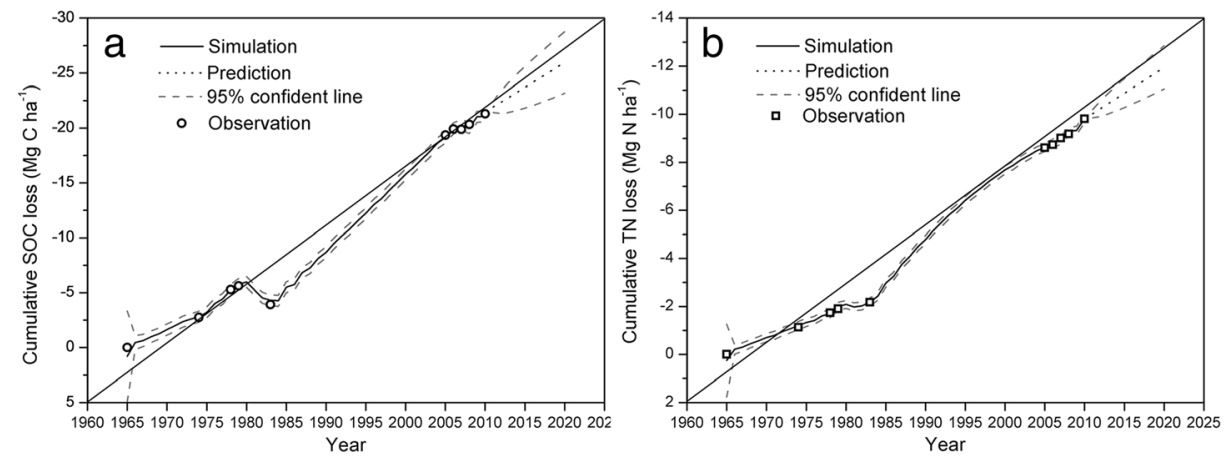

Fig. 4 Simulation and prediction of SOC (a) and TN (b) cumulative loss during the periods of 1965-2010 and 2011-2020 
Table 5 Mean effects of fertilization and cultivation duration on soil organic carbon and total nitrogen during the observation period (1965-1983, and 2005-2010)

\begin{tabular}{|c|c|c|c|c|c|c|}
\hline \multirow[t]{2}{*}{ Source of variation } & \multicolumn{3}{|c|}{ 1965-1983 } & \multicolumn{3}{|c|}{ 2005-2010 } \\
\hline & $\mathrm{df}$ & SOC & $\mathrm{TN}$ & $\mathrm{df}$ & $\mathrm{SOC}$ & $\mathrm{TN}$ \\
\hline Fertilizer utilizing (FU) & 1 & ** & *** & 1 & ** & * \\
\hline Crop system $(\mathrm{CS})$ & 2 & *** & *** & 1 & $* *$ & $* *$ \\
\hline \multicolumn{7}{|c|}{ Average concentrations of SOC and TN $\left(\mathrm{g} \mathrm{kg}^{-1}\right)$} \\
\hline Factors & & SOC & $\mathrm{TN}$ & Factors & & \\
\hline FU1 & & $24.615 \mathrm{~b}$ & $2.448 \mathrm{~b}$ & LFU & $20.920 \mathrm{~b}$ & $1.884 \mathrm{~b}$ \\
\hline FU2 & & $26.177 \mathrm{a}$ & $2.799 \mathrm{a}$ & HFU & $23.281 \mathrm{a}$ & $2.185 \mathrm{a}$ \\
\hline CS1 & & $25.334 \mathrm{c}$ & $2.620 \mathrm{c}$ & PR & $23.228 \mathrm{a}$ & $1.958 \mathrm{~b}$ \\
\hline CS2 & & $26.515 \mathrm{a}$ & $2.783 \mathrm{a}$ & $\mathrm{DC}$ & $21.374 \mathrm{~b}$ & $2.141 \mathrm{a}$ \\
\hline $\mathrm{CS} 3$ & & $25.600 \mathrm{~b}$ & $2.687 \mathrm{~b}$ & & & \\
\hline
\end{tabular}

FU1 no fertilizer with little organic manure, FU2, chemical fertilizer

$L F U$ low fertilization rate, $H F U$ high fertilization rate

CS1, CS2 and CS3 are the cropping systems as wheat-wheat-soybean, wheat-oilseed rape/fallow-soybean and maize-foxtail millet, respectively. $P R$, paddy rice, $D C$ dry cropland

${ }^{*}$ Significant at $P<0.05 ;{ }^{* *}$ Significant at $P<0.01 ;{ }^{* * *}$ Significant at $P<0.001$. Within each factor, means followed by different letter in the same column in a set are significantly different at $P<0.05$ (Fisher's protected LSD test; independent $t$-test, two-tailed)

$10^{3} \mathrm{~kg} \mathrm{~N}$ ha $^{-1}$ of $\mathrm{N}$ input), indicating SOC level shaped by $\mathrm{N}$ fertilization in seasonally frozen soils. When HFU was adopted, additional $5.0 \times 10^{3} \mathrm{~kg} \mathrm{C} \mathrm{ha}^{-1}$ of SOC and $632 \mathrm{~kg} \mathrm{~N} \mathrm{ha}^{-1}$ of TN were sequestered compared to LFU (Table 5). Applying chemical fertilizers without crop residues could lead to soil properties deterioration, which might retard SOC and TN accumulation and advance decreases (Malhi and Lemke 2007). But, high $\mathrm{N}$ fertilization rate accelerated organic matter decomposition in soils, and crop residues were the main C sources (Sainju et al. 2008).

Involvement of oilseed rape /fallow treatment in crop rotations significantly enhanced SOC and TN enrichment (Table 5). It was reported that green manure application with cover crops was conducive to nutrient maintenance and soil erosion reduction (Kanchikerimath and Singh 2001; Malhi and Lemke 2007). However, SOC and TN declines under fallow treatment with no-till were reported by Sainju et al. (2008). In this study, oilseed rape was cropped as green manure without autumn harvest in CS2. Moreover, unlike the bare fallow adopted by Sainju et al. (2008), fallow arrangement herein was moldboard plow. Cover vegetation was shallowly incorporated into soils as sources of $\mathrm{C}$ and $\mathrm{N}$ inputs. After massive biomass production was returned to soils, poorer contacts of $\mathrm{C}$ and $\mathrm{N}$ with soil particles led to decreased decomposition, which was propitious to $\mathrm{C}$ and $\mathrm{N}$ accumulation (Halvorson et al. 2002; Mazzoncini et al. 2011). However, Halvorson et al. (2002) emphasized that fallow could enhance decomposition rate and then reduce SOC. Sainju et al. (2008) also indicated that continuous cropping increased $\mathrm{C}$ and $\mathrm{N}$ sequestration compared to fallow due to intensive cycling. Therefore, the current frequency of fallow arrangement is recommended in our case. SOC and TN appreciably increased in CS3 compared with CS1. This could be explained by the difference of C input generated by crop residues, cover crops, underground biomass and rhizodeposition, because maize and foxtail millet residues generally return more biomass than wheat and soybean. Moreover, soybean decomposes faster due to its lower $\mathrm{C} / \mathrm{N}$ ratio. Turnover of maize root also serves a notable source of SOM. This relationship between soil C input and SOC and TN 
variations has been confirmed (Alvarez 2005; Halvorson et al. 2002). In the case of the shortterm cultivation, PR increased SOC level by $8.7 \%$ compared with DC equivalent to additional $\mathrm{C}$ sequestration of $3.9 \times 10^{3} \mathrm{~kg} \mathrm{C}^{-1}$, whereas accelerating TN loss (Table 5). In a national statistical analysis of China's cropland, SOC increased more frequently in PR than in DC (Pan et al. 2010). Our finding indicated the critical role of paddy rice plantation in $\mathrm{C}$ sequestration, which is consistent with previous studies (Malhi and Lemke 2007; Pan et al. 2010).

It is intriguing that dramatic augmentation in SOC and TN stocks occurred in 1983 (Fig. 3), accompanied by declined cumulative loss during 1980-1983 for SOC and during 1980-1981 for TN (Fig. 4). This might be partly ascribed to the improvements in fertilization rate and pattern. Chemical fertilizers such as granular triple superphosphate, diammonium phosphate and urea were increasingly applied since 1975 (Table 1). N fertilizer was reported to advance SOC enrichment, but only when crop residues were returned to soils (Alvarez 2005). In this study, the annals revealed that crop stubbles were not cleared before 1984. We speculate that fertilization-induced SOC enrichment was hysteretic, which could explain SOC augmentation appearing in years after chemical fertilizer application. Taking seasonal freeze-thaw events into account, cumulative SOC and TN losses, presenting growing trends could be partially interpreted. Even freeze-thaw cycle was favorable for $\mathrm{N}$ accumulation in agricultural soils, denitrification apparently occurred in surface soil during thawing periods. Presence of ice on soil appreciably promoted $\mathrm{N}$ dissipation. Both processes could accelerate $\mathrm{N}$ loss in the pathway of significant $\mathrm{N}_{2} \mathrm{O}$ flux (Ryan et al. 2000). Soil erosion was generally high during the spring thaw period and was enhanced by successive freeze-thaw cycles, particularly when soil water content was at a high level (Ferrick and Gatto 2005), promoting SOC and TN losses.

\section{Conclusions}

This study elucidated the temporal variability of SOC and TN under long-term conventional agricultural practices in seasonally frozen zones of northeastern China based on observations in the period of 1965-2010. After 45 years of cultivation, regional SOC and TN contents in the plow layer decreased by 15 and $42 \%$ respectively, with equivalent reductions of $2.1 \times 10^{3} \mathrm{~kg} \mathrm{ha}^{-1}$ for SOC and $9.8 \times 10^{3} \mathrm{~kg} \mathrm{ha}^{-1}$ for TN. Annual variations exhibited deteriorating tendencies with fluctuating levels ranging within -745 and $759 \mathrm{~kg} \mathrm{C}^{-1}$ year $^{-1}$ and -432 and $35 \mathrm{~kg} \mathrm{~N} \mathrm{ha}^{-1}$ year $^{-1}$, respectively. The SOC level was strictly shaped by $\mathrm{N}$ input following a regional pattern. Chemical fertilization with crop residue compost boosted SOC and TN accumulation, but facilitated their loss. Involvement of green manure/fallow treatment with 1-year frequency in crop rotations promoted $\mathrm{C}$ and $\mathrm{N}$ sequestration. Paddy management favored SOC accumulation. Time series modelling revealed that annual release rates of $468 \mathrm{~kg} \mathrm{ha}^{-1}$ for SOC and $214 \mathrm{~kg} \mathrm{ha}^{-1}$ for TN would continue in the subsequent 10 years, if the current conventional cultivation regimes were not changed. The generated algorithms derived from ARIMA model provided a pathway to estimate regional SOC and TN losses following cultivation and to evaluate soil fertility.

Acknowledgments The authors greatly appreciated financial support from the National Natural Science Foundation of China (No. 41171384, 41271414 and 41301529). We thank the staff in Land Consolidation and Rehabilitation Centre of Bawujiu Farm, for their help on field sampling and data collection. We also greatly appreciate the editor-in-chief and three anonymous reviewers whose comments have dramatically improved this paper. 


\section{References}

Alvarez R (2005) A review of nitrogen fertilizer and conservation tillage effects on soil organic carbon storage. Soil Use Manag 21:38-52

Bremner J (1960) Determination of nitrogen in soil by the Kjeldahl method. J Agric Sci 55:11-33

Brockwell PJ, Davis RA (2009) Time series: Theory and methods, 2nd edn. Springer, New York

Davidson EA, Janssens IA (2006) Temperature sensitivity of soil carbon decomposition and feedbacks to climate change. Nature 440:165-173

Ding W, Cai Z, Tsuruta H (2004) Cultivation, nitrogen fertilization, and set-aside effects on methane uptake in a drained marsh soil in Northeast China. Glob Chang Biol 10:1801-1809

Ferrick M, Gatto LW (2005) Quantifying the effect of a freeze-thaw cycle on soil erosion: laboratory experiments. Earth Surf Process Landf 30:1305-1326

Halvorson AD, Wienhold BJ, Black AL (2002) Tillage, nitrogen, and cropping system effects on soil carbon sequestration. Soil Sci Soc Am J 66:906-912

Heenan D, Chan K, Knight P (2004) Long-term impact of rotation, tillage and stubble management on the loss of soil organic carbon and nitrogen from a Chromic Luvisol. Soil Tillage Res 76:59-68

Horton NJ, Kleinman KP (2007) Much ado about nothing: a comparison of missing data methods and software to fit incomplete data regression models. Am Stat 61:79-90

Houghton R, Hackler J, Lawrence K (1999) The US carbon budget: contributions from land-use change. Science 285:574

Kanchikerimath M, Singh D (2001) Soil organic matter and biological properties after 26 years of maize-wheatcowpea cropping as affected by manure and fertilization in a Cambisol in semiarid region of India. Agric Ecosyst Environ 86:155-162

Lal R (2004) Soil carbon sequestration impacts on global climate change and food security. Science 304:16231627

Malhi S, Lemke R (2007) Tillage, crop residue and N fertilizer effects on crop yield, nutrient uptake, soil quality and nitrous oxide gas emissions in a second 4-year rotation cycle. Soil Tillage Res 96:269-283

Mazzoncini M, Sapkota TB, Bārberi P, Antichi D, Risaliti R (2011) Long-term effect of tillage, nitrogen fertilization and cover crops on soil organic carbon and total nitrogen content. Soil Tillage Res 114:165-174

Ng Kee Kwong K, Bholah A, Volcy L, Pynee K (2002) Nitrogen and phosphorus transport by surface runoff from a silty clay loam soil under sugarcane in the humid tropical environment of Mauritius. Agric Ecosyst Environ 91:147-157

Oztas T, Fayetorbay F (2003) Effect of freezing and thawing processes on soil aggregate stability. Catena 52:1-8

Pan G, Xu X, Smith P, Pan W, Lal R (2010) An increase in topsoil SOC stock of China's croplands between 1985 and 2006 revealed by soil monitoring. Agric Ecosyst Environ 136:133-138

Pu X, Cheng HG, Shan YS, Chen SY, Ding ZL, Hao FH (2012) Factor controlling soil organic carbon and total nitrogen dynamics under long-term conventional cultivation in seasonally frozen soils. Acta Agric Scand BS P 62:749-764

$\mathrm{Pu}$ X, Cheng HG, Tysklind M, Yang ST, Lin CY, Lu L, Xie J (2014) Responses of soil carbon and nitrogen to successive land use conversion in seasonally frozen zones. Plant Soil. doi:10.1007/s11104-014-2284-5

Ryan M, Kachanoski R, Gillham R (2000) Overwinter soil nitrogen dynamics in seasonally frozen soils. Can J Soil Sci 80:541-550

Sainju UM, Senwo ZN, Nyakatawa EZ, Tazisong IA, Reddy KC (2008) Soil carbon and nitrogen sequestration as affected by long-term tillage, cropping systems, and nitrogen fertilizer sources. Agric Ecosyst Environ 127:234-240

Six J, Bossuyt H, Degryze S, Denef K (2004) A history of research on the link between (micro) aggregates, soil biota, and soil organic matter dynamics. Soil Tillage Res 79:7-31

Smith P (2008) Land use change and soil organic carbon dynamics. Nutr Cycl Agroecosyst 81:169-178

Smith K, Jackson D, Pepper T (2001) Nutrient losses by surface run-off following the application of organic manures to arable land. 1. Nitrogen. Environ Pollut 112:41-51

Smith P, Martino D, Cai Z, Gwary D, Janzen H, Kumar P, McCarl B, Ogle S, O’Mara F, Rice C, Scholes B, Sirotenko O, Howden M, McAllister T, Pan G, Romanenkov V, Schneider U, Towprayoon S (2007) Policy and technological constraints to implementation of greenhouse gas mitigation options in agriculture. Agric Ecosyst Environ 118:6-28

Sodhi G, Beri V, Benbi D (2009) Soil aggregation and distribution of carbon and nitrogen in different fractions under long-term application of compost in rice-wheat system. Soil Tillage Res 103:412-418

Song G, Li L, Pan G, Zhang Q (2005) Topsoil organic carbon storage of China and its loss by cultivation. Biogeochemistry 74:47-62

Tiessen H, Cuevas E, Chacon P (1994) The role of soil organic matter in sustaining soil fertility. Nature 371:783-785 
Tinsley J (1950) The determination of organic carbon in soils by dichromate mixtures. Transl Int Congr Soil Sci 1:161-164

Wu H, Guo Z, Peng C (2003) Land use induced changes of organic carbon storage in soils of China. Glob Chang Biol 9:305-315

Zhang GP (2003) Time series forecasting using a hybrid ARIMA and neural network model. Neurocomputing 50:159-175

Zhu B, Peng K, Xie H (2006) Nitrogen balance of agro-ecosystem in a typical watershed in the hilly area of central Sichuan Basin. Chin J Eco-Agric 14:108-111 